\title{
Support Vector Machines for the Estimation of Specific Charge in Tunnel Blasting
}

\author{
Aref Alipour $^{1 *}$, Mojtaba Mokhtarian-Asl ${ }^{1}$, Mostafa Asadizadeh ${ }^{2}$ \\ ${ }^{1}$ Faculty of Mining Engineering, Urmia University of Technology, Urmia, P.O. Box 57166-17165, Iran \\ ${ }^{2}$ Department of Mining Engineering, Hamedan University of Technology, Hamedan, 65155-579, Iran \\ * Corresponding author, e-mail: a.alipour@mie.uut.ac.ir
}

Received: 02 January 2021, Accepted: 12 April 2021, Published online: 07 May 2021

\begin{abstract}
Mine tunnels, short transportation tunnels, and hydro-power plan underground spaces excavations are carried out based on Drilling and Blasting (D\&B) method. Determination of specific charge in tunnel D\&B, according to the involved parameters, is very significant to present an appropriate $D \& B$ design. Suitable explosive charge selection and distribution lead to reduced undesirable effects of $D \& B$ such as inappropriate pull rate, over-break, under-break, unauthorized ground vibration, air blast, and fly rock. So far, different models are presented to estimate specific charge in tunnel blasting. In this study, 332 data sets, including geomechanical characteristics, D\&B, and specific charge are gathered from 33 tunnels. The data are related to three dams and hydropower plans in Iran (Gotvand, MasjedSolayman, and Siah-Bishe). Specific charge is modeled in inclined hole cut drilling pattern. In this regard, Support Vector Machine (SVM) algorithm based on polynomial Kernel function is used as a tool for modeling. Rock Quality Designation (RQD) index, Uniaxial Compressive Strength (UCS), tunnel cross-section area, maximum depth of blast hole, and blast hole coupling ratio are considered as independent input variables and the specific charge is considered as a dependent output variable. The modeling results confirm the acceptable performance of SVM in specific charge estimation with minimum error.
\end{abstract}

\section{Keywords}

tunnel, drilling and blasting, specific drilling, Support Vector Machine

\section{Introduction}

Drilling and Blasting, D\&B, is a traditional method for rock excavation in underground and surface excavations. Tunnels are greatly used in mining as well as civil engineering, e.g., transport tunnels, water transfer tunnels, underground power planets and, etc. Large mountain chains in Iran necessitate many tunnel constructions, in different shapes and sizes, for various applications. D\&B method is more suitable for most cases, comparing to mechanized excavation, due to its significant flexibility, low investment cost, and not demanding high technology. The efficiency of any blasting operation is affected by the interaction between explosive materials and rock mass [1-6]. Thus, knowledge of rock parameters can lead to optimization of blast results and specific charge. Parameters that affect blast results are categorized as follows [7]:

- Explosive specifications

- Rock mass specifications

- Geometry of drilling pattern
Generally, despite the history of studies related to D\&B, due to the complexity of the involved parameters, no significant scientific progress has been observed in this field [2]. Numerical and analytical methods in this field have not worked well, and progresses are almost related to empirical analyses. Some related results are reported in [1, 7-21].

Specific charge as the amounts of explosives used per cubic meters of extracted rock is the most important parameter in D\&B operations. Different models have been proposed for estimation of specific charge, most of which are empirically developed through regression analysis methods. Type of explosive, rock mass characteristics and geometry of blast pattern are the main parameters, affecting the specific charge. Table 1 shows a list of the main parameters incorporated in different models, developed for both surface and underground blasting models. Some parameters may affect the blast results internationally with other parameters, e.g., Uniaxial Compressive Strength (UCS), 
Table 1 Parameters are operating in some specific charge estimation models

\begin{tabular}{|c|c|c|c|}
\hline Model developed by & Parameters considered in models & Application & Year \\
\hline Du Pont $[10]$ & $\begin{array}{c}\text { Tunnel area } \\
\text { Blast hole diameter }\end{array}$ & Tunnel blasting & 1977 \\
\hline Langefors \& Kihlstrom [15] & $\begin{array}{l}\text { Tunnel area } \\
\text { Drilling error }\end{array}$ & Tunnel blasting & 1978 \\
\hline Pokrovsky [18] & $\begin{array}{c}\text { Tunnel area } \\
\text { Protodyakonov Index } \\
\text { Rock structure } \\
\text { Relative weight strength of explosive } \\
\text { Explosive (charge) diameter }\end{array}$ & Tunnel blasting & 1980 \\
\hline Lilly [16] & $\begin{array}{l}\text { Rock Mass Description } \\
\text { Joint spacing } \\
\text { Joint orientation } \\
\text { Specific gravity of rock } \\
\text { Hardness }\end{array}$ & Surface blasting & 1986 \\
\hline Ghose [11] & $\begin{array}{l}\text { Density of rock } \\
\text { Protodyakonov Index } \\
\text { Joint spacing } \\
\text { Joint orientation }\end{array}$ & Surface blasting & 1988 \\
\hline Olofsson [17] & Tunnel area & Tunnel blasting & 1988 \\
\hline Hagan [12] & $\begin{array}{c}\text { Tunnel area } \\
\text { Blast hole diameter }\end{array}$ & Tunnel blasting & 1992 \\
\hline JKMRC [13] & $\begin{array}{c}\text { Rock strength } \\
\text { Rock density } \\
\text { Rock Young's modulus } \\
\text { Average in situ block size } \\
\text { Target fragment size } \\
\text { Ground water rate }\end{array}$ & Surface blasting & 1992 \\
\hline Chakraborty et al. [8] and [9] & $\begin{array}{c}\text { Rock Mass Quality (Q) } \\
\text { Strength Rating } \\
\text { Number of contact surfaces } \\
\text { Hole length }\end{array}$ & Tunnel blasting & 1997 and 1998 \\
\hline Kahriman et al. [14] & Bond work index & Surface blasting & 2001 \\
\hline Raina et al. [19] & $\begin{array}{c}\text { P-wave velocity } \\
\text { Number of contact surfaces in multiple geological } \\
\text { mixed face condition } \\
\text { RQD } \\
\text { Tunnel area } \\
\text { Inclination } \\
\text { Cut hole angle } \\
\text { Coupling ratio }\end{array}$ & Tunnel blasting & 2004 \\
\hline Ryu et al. [20] & $\begin{array}{c}\text { Protodyakonov index } \\
\text { Blast coefficient } \\
\text { Crater index } \\
\text { 1 height of total fragments with size under } 0.5 \mathrm{~mm} \\
\text { after drop impact. }\end{array}$ & Tunnel blasting & 2006 \\
\hline Alipour et al. [7] & $\begin{array}{l}\text { P-wave velocity } \\
\text { RQD } \\
\text { Tunnel area } \\
\text { Coupling ratio } \\
\text { Blast hole depth }\end{array}$ & Tunnel blasting & 2012 \\
\hline
\end{tabular}

P-wave velocity, and rock density. Determination of governing parameters for every model and their extents influence has to be made by the experts who apply the models. It should be noted that the measurement of some parameters is difficult and/or expensive. The ratio of the radius of the crater in Ryu et al. model [20], dynamic strength and dynamic modules of rock in Han et. al model are some examples [22]. An ideal model should employ the most important parameters. However, simplicity in obtaining these parameters should be considered as a priority. 
In recent years, less attention has been paid to blast-ability and specific charge estimation in tunnel blasting. In one of the recent studies, in addition to 70-year reviews, the difficulty of tunneling with D\&B method was carried out in different rocks quantitatively. From tunneling difficulty degree perspective, six different classes were defined. However, it is necessary to conduct new studies in this field [23]. Some of the papers in tunnel D\&B area in recent years are as follows [24-26]:

Support Vector Machine (SVM), as one of the powerful tools, has been able to bring advantages for solving engineering problems. Application of SVM, as a pattern recognizer for non-linear behavior estimation of the specific charge, in underground excavations, forms the core of this research. Using suitable input parameters could lead to a reliable SVM model for accurate estimation of specific charge in tunneling.

\section{The characteristics of the excavated tunnels}

The data sets are gathered from Gotvand and MasjedSolayman (in Iran Khuzestan province) and Siah-Bishe (in Iran Mazandaran province) dams and hydropower plans. These first two projects, in addition to the dam, include spillway, deviation tunnels, grouting tunnels, tailrace and headrace tunnels, underground cavern, and related structures. Siah-Bishe pump-storage project includes two dams, power plant caverns, and related underground excavations. In Fig. 1, the locations of case studies are characterized.

Following methodologies were adopted by authors during data collection:

- In the studied cases, for large underground space excavation and large and medium-sized tunnels, heading-benching tunneling method was used. Also, for larger excavation such as power caverns, multistage tunneling methods have been used. In this study, heading sections (one free faces) of 33 tunnels are surveyed that are tunneling with variable areas.

- The investigated tunnels were categorized into various zones based on their RMR Values.

- Data of similar tunnels are ignored as far as possible.

- The total length of tunnels was not used for case analysis and only the data of areas with geomechanical characteristics change were recorded. Total tunnel length was divided into different zones, and according to the zones changes, data were recorded. In Table 2, a list of excavated tunnels in different sites with the properties related to the geological formation, rock type, and RMR index value are

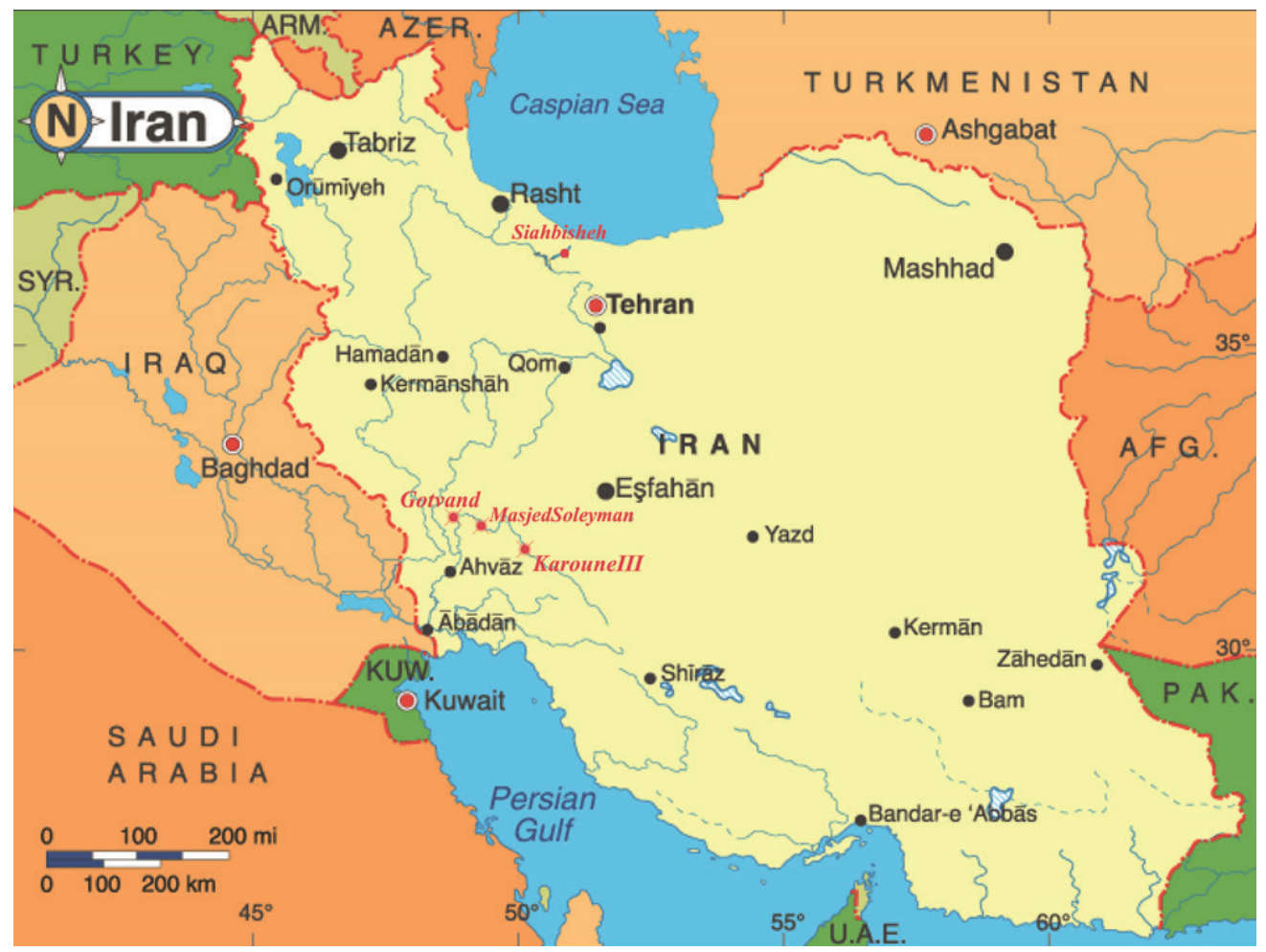

Fig. 1 Geographical situation of case studies, consist of 33 tunnels in Iran 
Table 2 Investigated sites and their geo-mining conditions

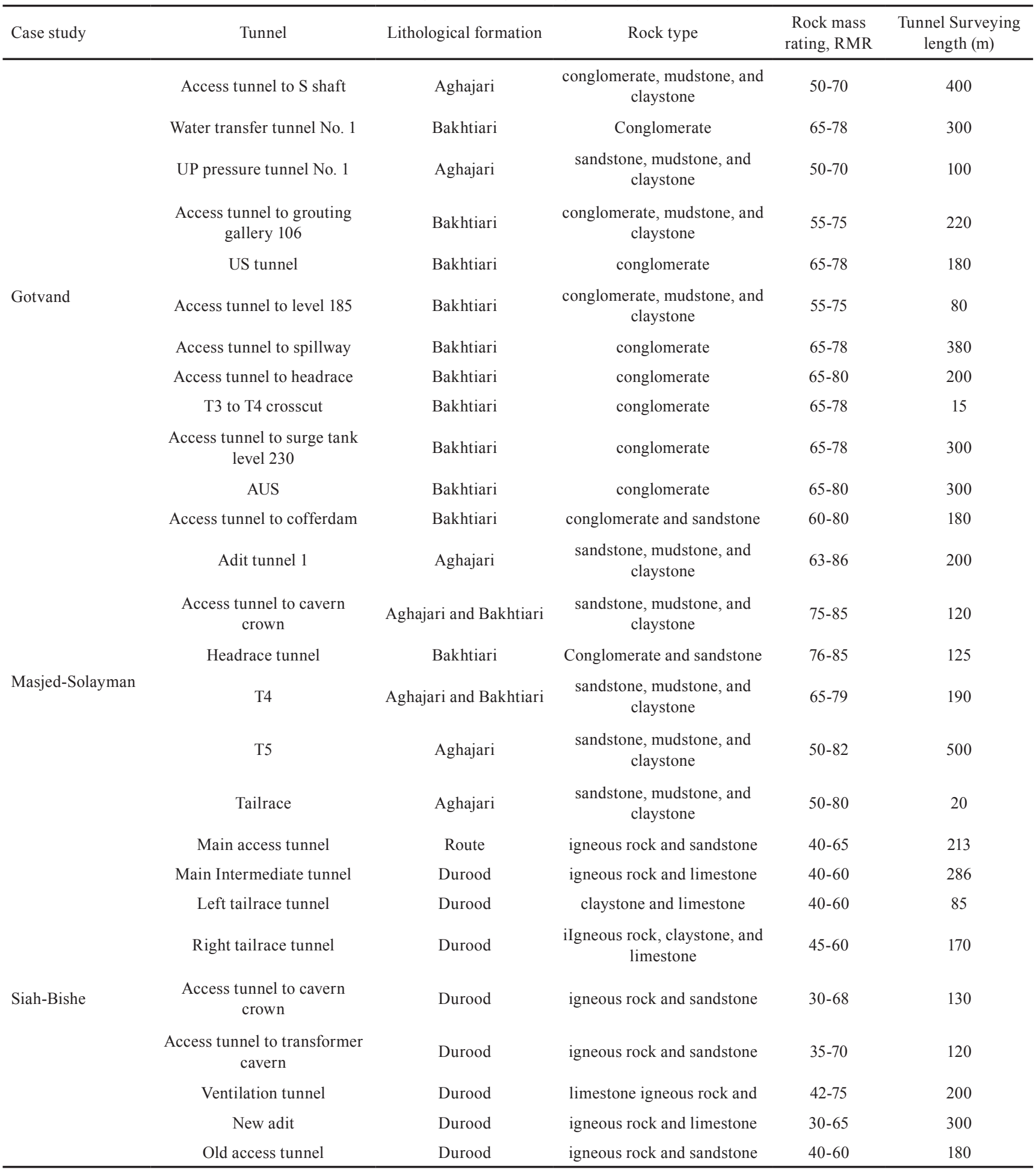

presented.

- The lengths of the tunnel were thoroughly inspected. But the initial section of the tunnel, which was mostly consisted as weathered rock masses, was excluded.

- Necessary geomechanical data were gathered according to geomechanical and geological reports of consultant engineers, drillings by contractors, assumed information before and during execution, local experiments, and judgments of resident engineers.

- Face advance in each round was measured at the tunnel face center and the two sides of the face. The average of these values was considered as the average advance per round. The excavated in situ volume was calculated by multiplying the post-blast cross-section and average face advance. The specific charge was estimated from the ratio of total explosive quantity 
in a round and the excavated in situ volume of rock. Also, the blast results of different rounds in a particular zone were averaged to determine the average blast results in that zone.

- Trial blasts were conducted in these sites with modified blast design, and the results were monitored by the investigators.

- Detailed information on on-going blasting practice and blast results in various rounds were collected by the investigators. Face advance in a round was measured at the face center and the two sides of the face. The average of these values was considered as the average advance per round. The blast results of different rounds in a particular zone were averaged to determine the average blast results in the whole zone. To determine particular zone pull rate (depth of D\&B round) in different cycles, average pull efficiencies of three continuous rounds were considered as pull rate.

- Two dynamites with the diameters of 22 and $30 \mathrm{~mm}$ were used. The used dynamites were Akhgar dynamites made by Parchine Company. Sometimes, due to lack of access, dynamites with different brands were used such as Emolite, Geophex, and Gorytes and the related data were ignored. Production specifications of Akhgar dynamite are as follows: these explosive materials are a mixture of Nitroglycerin, Nitrocellulose, Ammonium nitrate, and other additives. These materials, due to high resistance against moisture, power, density, and suitable combustion velocity are the best explosive materials to hard rock extraction and can be used in the holes filled with water. Power specifications, effective energy relative to ANFO, cartridge density, and velocity of detonation of Akhgar dynamite are $1.25-1.4\left(\mathrm{~g} / \mathrm{cm}^{3}\right)$, and 4000-5000 (m/s), respectively.

- Explosive detonators were exclusive to electric detonators of $250 \mathrm{~ms}$ and $500 \mathrm{~ms}$.

- Blast holes were drilled using the two-armed jumbo drill.

- The diameters of the blast holes were 45 and $51 \mathrm{~mm}$. Generally, Gotvand holes were $45 \mathrm{~mm}$ and MasjedSolayman, and Siah-bishe holes were $51 \mathrm{~mm}$.

- Blast hole charging was carried out continuously.

- Stemming is consistent with the hole length, about 20 to $30 \%$ of total blast hole length.

- Gathered data related to D\&B were extracted from the documents available in explosive materials storage documents, D\&B pattern form, mapping unit surveys, and tunneling progress reports in different cases. Blasting information of each round included pull rate, specific charge, consumed explosive materials, and other information.

- The ratio of the explosive diameter to the hole-diameter is known as the blast-hole coupling ratio. In this research, coupling ratio is considered as independent input variable.

- D\&B in Tunneling can commonly be classified as two groups: parallel cut and inclined cut. In different cases, inclined cut drilling pattern according to Fig. 2 was used in which the central holes are V-shaped and in lateral parts, we have a parallel arrangement. In Fig. 2, the arrangement of blast holes in a relatively fixed pattern is presented. In cases in which the arrangement is different, data are not taken into consideration.

To match D\&B data of each blasting cycle with geomechanical characteristics of the site, geological mappings prepared at the technical office were used. First, the tunnels were zoned according to geomechanical conditions change and explosives in different zones. Finally, the integration of geomechanical information, D\&B specifications, and measured specific charge related to tunnel length were used to model the specific charge.

\section{The role of influencing parameters}

Based on the field investigations and the literature review, a list of influencing parameters and their values has been collected. Database properties and the range of the variables are presented graphically in Fig. 3. Also, the data were analyzed to study the effect of each parameter on the specific charge. Fig. 3 shows the variation of 5 different parameters versus specific charge for 332 sets of data.

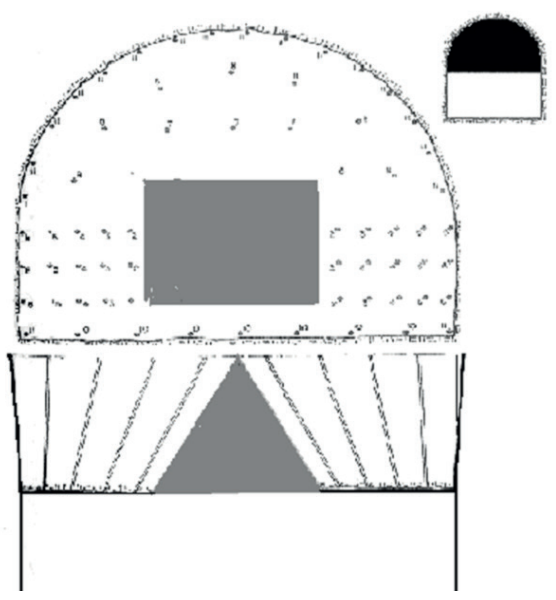

Fig. 2 Fixed inclined cut D\&B pattern (V-cut) in different cases 


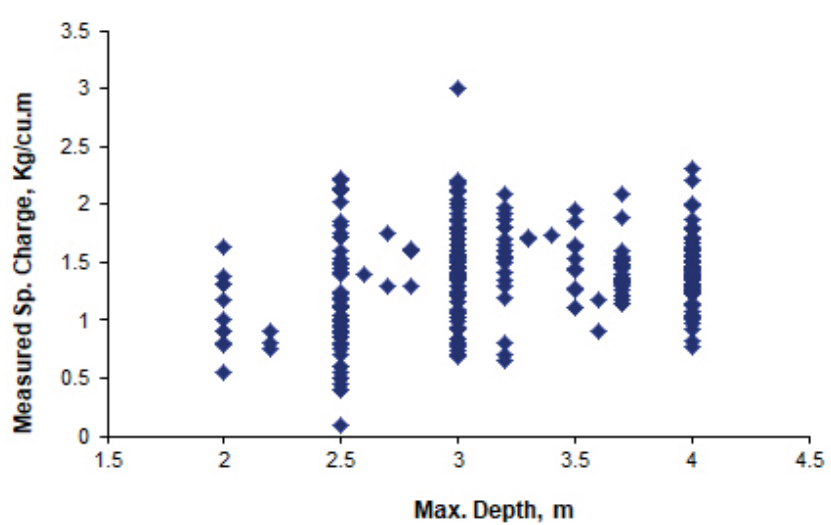

(a)

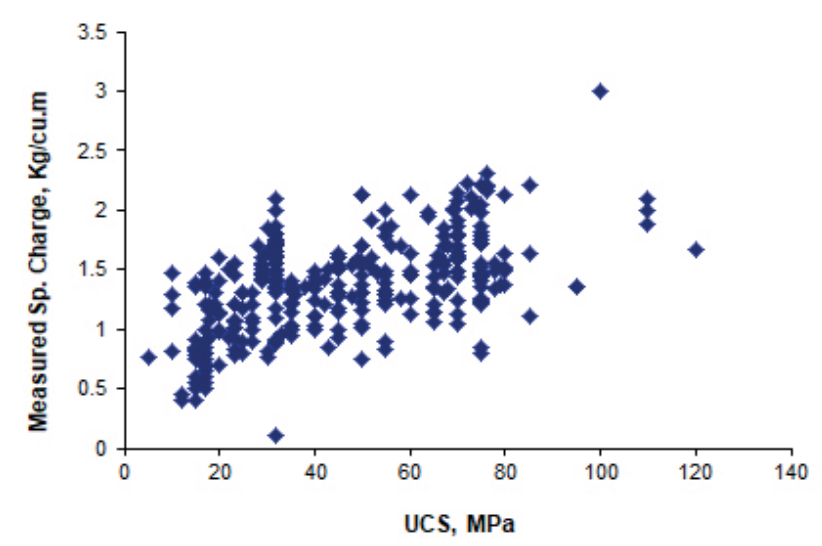

(c)

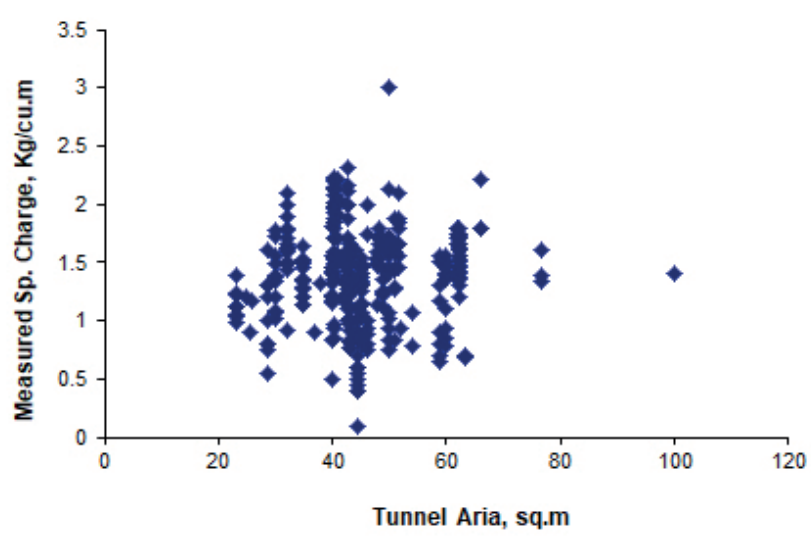

(b)

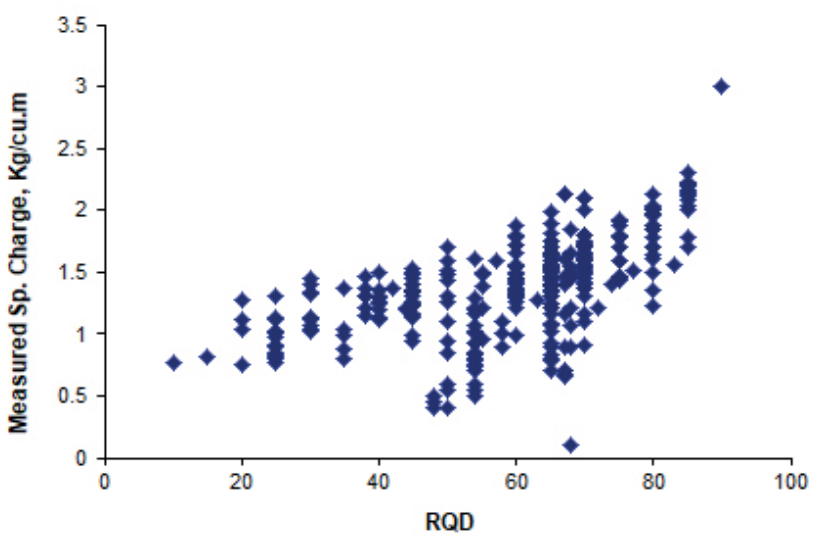

(d)

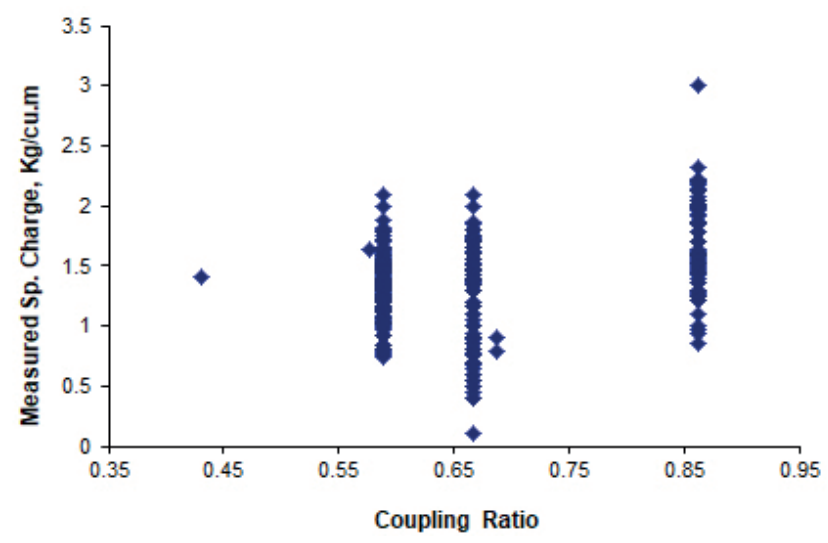

(e)

Fig. 3 The role of various parameters on specific charge a) Max. depth; b) Tunnel Aria; c) UCS; d) RQD; e) Coupling ratio

However, these figures show only a general trend and are not aimed to quantify any equations. No definite correlations are seen in the figures. The data are more scattered. Although with increased tunnel cross section area, reduction in specific charge is clear, for tunnels with the area of $40 \mathrm{~m}^{2}$ and specific charge varies between 0.5 and $2.5 \mathrm{~kg} / \mathrm{m}^{3}$. Extensive changes in specific charge in this cross section indicate the role of other effective parameters. The modeling of specific charge is valid when all the affective parameters are considered. Therefore, a comprehensive model is a model that estimates specific charge by integrating all effective parameters with appropriate weighting.

\section{Support Vector Machine}

Support vector machine is one of the new methods to solve classification and regression problems. This method is based on a statistical theory [27]. SVM algorithm is one of the machine learning algorithms among training methods 
with classified supervision that creates connection between independent variables, and dependent variable based on structural risk minimization [28, 29]. In neural networks method, empirical risk minimization based on error reduction is used during training process. In this algorithm, unlike neural networks, this problem has been solved and by structural risk minimization, problems in local minima are fewer, and the generalizability is higher [30].

In regression problems, SVM maps the input vectors to a multidimensional feature space. Then, it creates a hyper plane that separates the input vectors with the maximum possible distance. Indeed, the objective of SVM is estimation of weight parameters and bios is a function that has the best consistency with data. This function can be linear or nonlinear. Assuming we have $l$ training data, and each $\boldsymbol{X}$ input has $D$ features (that is $D$ number dimensions, and each point has a special value like $Y$ ), the objective is to find a regression function that creates the following equation between input, and output [31, 32].

$f(\boldsymbol{x}, \boldsymbol{w})=(\boldsymbol{w} \cdot \boldsymbol{x})+b$

To obtain function $f$, it is necessary to estimate bios $b$, and weight $\boldsymbol{w}$ vector values. At first, a loss function with the coverage area $\varepsilon$ is defined as Eq. (2): $\boldsymbol{L}_{\varepsilon}$ function is Vapnik loss function; using this function, SVM response function controller parameters including weight and bios are obtained:

$\boldsymbol{L}_{\mu}(y)=|y-f(\boldsymbol{x}, \boldsymbol{w})|_{\varepsilon}=\left\{\begin{array}{ll}0 \rightarrow i f & |y-f(\boldsymbol{x}, \boldsymbol{w})|_{\varepsilon} \leq \varepsilon \\ |y-f(\boldsymbol{x}, \boldsymbol{w})|-\varepsilon, \text { Otherwise }\end{array}\right.$.

For this purpose, Eq. (3) should be minimized:

$\boldsymbol{R}(C)=\frac{1}{2}\|\boldsymbol{w}\|^{2}+C \frac{1}{l} \sum_{i=1}^{l} \boldsymbol{L}_{\mu}\left(y_{i}, f_{i}(\boldsymbol{x}, \boldsymbol{w})\right)$.

For a better description, Eq. (3) is written as Eq. (4) set: Min

$\Phi\left(\boldsymbol{w}, \zeta^{*}, \zeta\right)=\frac{1}{2}\|\boldsymbol{w}\|^{2}+C\left(\sum_{1}^{i} \zeta^{*}+\sum_{1}^{i} \zeta\right)$

Sub.

$y_{i}-((\boldsymbol{w} \cdot \boldsymbol{x})+b) \leq \varepsilon+\zeta_{i}$

$\left(\left(\boldsymbol{w} \cdot \boldsymbol{x}_{i}\right)+b\right)-y_{i} \leq \varepsilon+\zeta^{*}, i=1,2,3, i$

$\zeta^{*}, \zeta \geq 0$

In Eqs. (3) and (4), $C$ is capacity or penalty parameter that its value should be regulated by the user. Indeed, this parameter is responsible to create balance, and change the penalty weights after bios, and has variable $\varepsilon$ and at the same time, determines maximum separation margin. The variable $\varepsilon$ is acceptable error in losses, $\|\boldsymbol{w}\|^{2}$ is soft weight vector, $\zeta^{*}$ and $\zeta$ are slack variables. This problem can be solved using Lagrange method. Therefore, by converting into the Lagrange function as maximization, Eq. (5) is rewritten as:

$$
\begin{aligned}
& \boldsymbol{L}_{p}\left(\alpha_{i}, \alpha_{i}^{*}\right)=-\left(\frac{1}{2}\right) \sum_{i, j=1}^{l}\left(\alpha_{i}-\alpha_{i}^{*}\right)\left(\alpha_{i}-\alpha_{i}^{*}\right) \boldsymbol{x}_{i} \boldsymbol{x}_{j} \\
& -\varepsilon \sum_{i=1}^{l}\left(\alpha_{i}+\alpha_{i}^{*}\right)+\sum_{i=1}^{l}\left(\alpha_{i}-\alpha_{i}^{*}\right) y_{i}
\end{aligned}
$$

In these equations, $\boldsymbol{L}_{p}\left(\alpha_{i}, \alpha_{i}^{*}\right)$ is Lagrange function, $\alpha_{i}, \alpha_{i}^{*}$ are Lagrange coefficients, and its constraints are as follows:

$\sum_{i=1}^{l}\left(\alpha_{i}-\alpha_{i}^{*}\right)=0 \rightarrow \begin{gathered}0 \leq \alpha_{i} \leq C, i=1, \ldots, l \\ 0 \leq \alpha_{i}^{*} \leq C, i=1, \ldots, l\end{gathered}$

By solving Eq. (6), SVM function can be estimated using kernel function as follows:

$f(\boldsymbol{x}, \boldsymbol{w})=\boldsymbol{w}_{0} \cdot \boldsymbol{x}+b=\sum_{i=1}^{l}\left(\alpha_{i}-\alpha_{i}^{*}\right) \boldsymbol{x}_{i} \cdot \boldsymbol{x}+b_{0}$.

By determining $\alpha_{i}$ and $\alpha_{i}^{*}$, the final response from Eqs. (8) and (9) is obtained:

$\boldsymbol{w}_{0}=\sum_{i=1}^{l}\left(\alpha_{i}-\alpha_{i}^{*}\right) \boldsymbol{x}_{i}$

$b_{0}=-\left(\frac{1}{2}\right) \boldsymbol{w}_{0} \cdot\left[\boldsymbol{x}_{r}+\boldsymbol{x}_{s}\right]$

In these equations, $\boldsymbol{w}_{0}$ and $b_{0}$ are optimal values of weight and bios, and $\boldsymbol{x}_{r}$ and $\boldsymbol{x}_{s}$ are support vectors. Data that their corresponding Lagrange coefficients are nonzero are known as support vector. Geometrically, these data have prediction error larger than $\pm \varepsilon$. $\varepsilon$ controls support vectors. Finally, support vectors determine the final regression function with optimal response. $\varepsilon$ can accept zero to the infinity values. Large $\varepsilon$ values reduce support vectors that occur with band broadening and increases allowed error domain. Small $\varepsilon$ values increase support vectors and over-training probability.

Linear regression problem can become non-linear using Kernel functions [33]. Polynomial kernel functions, radial base function, and Pearson Kernel function have been applied in some of geomechanic problems successfully [34-38]. In this study, simple polynomial Kernel function has been used and its Eqs. (8) and (9) are rewritten as follows [33]: 
$\boldsymbol{w}_{0} \cdot \boldsymbol{x}=\sum_{i=1}^{l}\left(\alpha_{i}-\alpha_{i}^{*}\right) \boldsymbol{K}\left(\boldsymbol{x}_{i}, \boldsymbol{x}\right)$,

$b_{0}=-\left(\frac{1}{2}\right) \sum_{i=1}^{l}\left(\alpha_{i}-\alpha_{i}^{*}\right)\left[\boldsymbol{K}\left(\boldsymbol{x}_{r}, \boldsymbol{x}_{i}\right)+\boldsymbol{K}\left(\boldsymbol{x}_{s}, \boldsymbol{x}_{i}\right)\right]$.

In these equations, $\boldsymbol{K}\left(\boldsymbol{x}, \boldsymbol{x}_{i}\right)$ is a Kernel function. Polynomial Kernel function used in this study is as follows:

$\boldsymbol{K}\left(\boldsymbol{x}, \boldsymbol{x}_{i}\right)=\left(\left(\boldsymbol{x}, \boldsymbol{x}_{i}\right)+1\right)^{d}$,

where $d$ is polynomial power and is characterized according to user's opinion.

\section{Specific charge estimation using SVM}

SVM can find the relationship between effective parameters, and specific charge by observing sufficient data with suitable distributive, and measured domain. According to the ability to detect non-linear patterns using this machine, good results can be achieved. For this purpose, 332 data series related to geomechanic, D\&B, and specific charge were gathered for modeling. In the suggested model, some of important accessible and effective parameters including RQD, UCS (MPa), tunnel cross section area $\left(\mathrm{m}^{2}\right)$, maximum depth of blast hole (m), and blast hole coupling ratio were used as SVM input. Therefore, 332 data series separated into 200 training data sets and 132 test data sets, and SVM training was carried out. Polynomial function, according to the past successful experiences was used as the selected kernel function and to achieve the optimal model, different combinations of important regulator parameters including $\mathrm{C}, \varepsilon$ and $\mathrm{d}$ were used in the model. Finally, these parameters were determined in the optimal model with minimum error of $1.5,0.03$, and 4. SVM model characteristics after several repetition steps for the study program are presented in Table 3.

\begin{tabular}{lc}
\multicolumn{2}{c}{ Table 3 Characteristics of SVM model } \\
\hline Parameter & Description \\
\hline No. training data & 232 \\
No. testing data & 100 \\
Kerenel function & Polynomial \\
$C$ & 1.5 \\
$\varepsilon$ & 0.035 \\
$d$ & 4 \\
Mean square error of training & 0.02051 \\
Mean square error of testing & 0.02035 \\
Mean absolute error of training & 0.1102 \\
Mean absolute error of testing & 0.1137 \\
\hline
\end{tabular}

For graphical comparison, the results of SVM estimation with real values are shown in Fig. 4. In this figure, scattering from the central diagonal line indicates deviation value or modeling error. The lines on both sides of this line indicate $20 \%$ error that shows $20 \%$ difference between real value and estimated value. As it can be observed, for many datasets, training data and testing data of machine estimation values are less than $20 \%$.

\section{Conclusions}

SVM, with access to satisfactory number of data, is a powerful tool to model non-linear systems. Comparison of real measured values and estimated specific charge according to

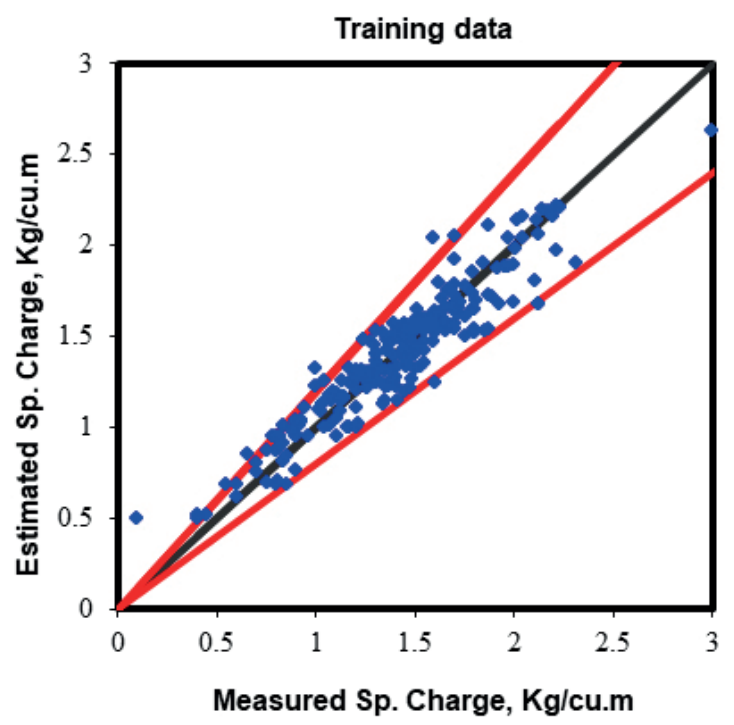

(a)

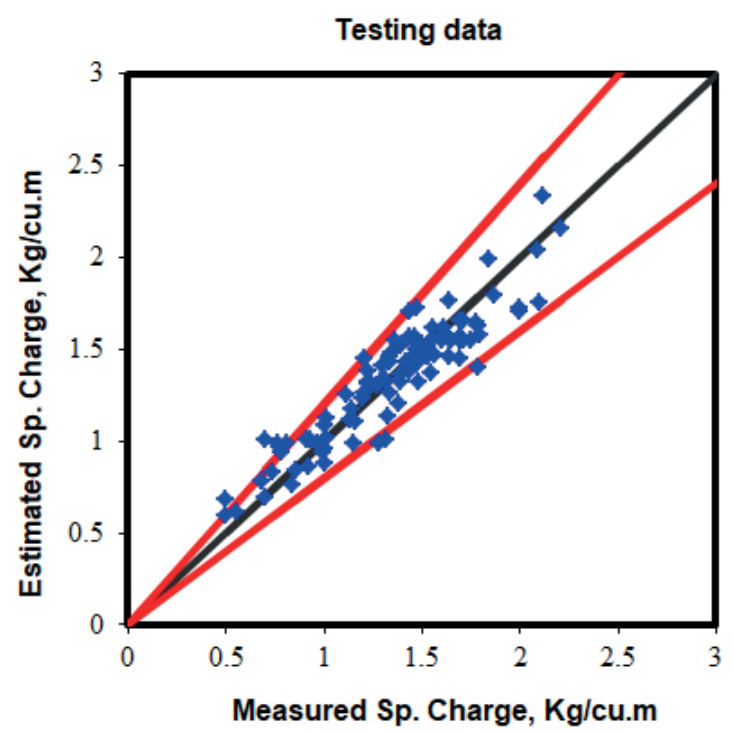

(b)

Fig. 4 Estimation of specific charge using SVM versus measured values, agreement between the estimated and measured values is within $\pm 20 \%$ for most measurements separately for training and testing data 
this method indicates low error of the above method. Coefficient of correlation and Mean absolute error estimation error values of the training period were 0.93 and 0.1102 , and in testing period, these values were 0.92 and 0.1137 , respectively. Proximity of estimation error in training and testing steps indicates correct SVM training. There were small changes in the inclined hole cuts D\&B pattern (arrangement of V-shaped holes) including drilled holes angle, type of charging, and other some constant parameters

\section{References}

[1] Alipour, A., Mokharian, M., Chehreghani, S. "An Application of Fuzzy Sets to the Blastability Index (BI) Used in Rock Engineering", Periodica Polytechnica Civil Engineering, 62(3), pp. 580-589, 2018. https://doi.org/10.3311/PPci.11276

[2] Alipour, A., Mokhtarian, M., Abdollahei Sharif, J. "Artificial neural network or empirical criteria? A comparative approach in evaluating maximum charge per delay in surface mining - Sungun copper mine", Journal of the Geological Society of India, 79(6), pp. 652658, 2012.

https://doi.org/10.1007/s12594-012-0102-3

[3] Amiri, M., Hasanipanah, M., Bakhshandeh Amnieh, H. "Predicting ground vibration induced by rock blasting using a novel hybrid of neural network and itemset mining", Neural Computing and Applications, 32, pp. 14681-14699, 2020.

https://doi.org/10.1007/s00521-020-04822-w

[4] Hosseinzadeh Gharehgheshlagh, H., Alipour, A. "Ground vibration due to blasting in dam and hydropower projects", Rudarskogeološko-Naftni Zbornik, 35(3), pp. 59-66, 2020.

https://doi.org/10.17794/rgn.2020.3.6

[5] Mokhtarian Asl, M., Alipour, A. "A nonlinear model to estimate vibration frequencies in surface mines", International Journal of Mining and Geo-Engineering, 54(2), pp. 167-171, 2020.

https://doi.org/10.22059/ijmge.2019.276445.594785

[6] Rezaeineshat, A., Monjezi, M., Mehrdanesh A., Khandelwal, M. "Optimization of blasting design in open pit limestone mines with the aim of reducing ground vibration using robust techniques", Geomechanics and Geophysics for Geo-Energy and Geo-Resources, 6(2), Article number: 40, 2020.

https://doi.org/10.1007/s40948-020-00164-y

[7] Alipour, A., Jafari, A., Hossaini, S. M. F. "Application of ANNs and MVLRA for Estimation of Specific Charge in Small Tunnel", International Journal of Geomechanics, 12(2), pp. 189-192, 2012. https://doi.org/10.1061/(ASCE)GM.1943-5622.0000125

[8] Chakraborty, A. K., Jethwa, J. L., Dhar, B. B. "Predicting powder factor in mixed-face condition: development of a correlation based on investigations in a tunnel through basaltic flows", Engineering Geology, 47(1-2), pp. 31-41, 1997. https://doi.org/10.1016/S0013-7952(96)00117-2

[9] Chakraborty, A. K., Roy, P. P., Jethwa, J. L., Gupta, R. N. "Blast performance in small tunnels-a critical evaluation in underground metal mines", Tunnelling and Underground Space Technology, 13(3), pp. 331-339, 1998. affecting specific charge. Only effective parameters (independent variables) including RQD, UCS, maximum depth of hole, blast hole coupling ratio and tunnel cross section area were considered in the tunnel D\&B specific charge modeling. The use of complementary geomechanical parameters such as rock mass joints specification, more accurate $D \& B$ sampling such as pull rate, exact consumed explosive materials, and applying the details of holes arrangement in D\&B pattern can increase the model's accuracy.

[10] The Technical Service Section of the Explosives Department "Blasters' Handbook", E. I. Du Pont De Nemours \& Company, Wilmington, DE, USA, 1977.

[11] Ghose, A. K. "Design of drilling and blasting subsystems - a rock mass classification approach", In: Proceedings of International Symposium on Mine Planning \& Equipment Selection, Calgary, Canada, 1988, pp. 335-340.

[12] Hagan, T. N. "Safe and cost-efficient drilling and blasting for tunnels, caverns, shafts and raises in India", In: Proceedings of a Workshop on Blasting Technology for Civil Engineering Projects, New Delhi, India, 1992, pp. 16-18.

[13] Julius Kruttschnitt Mineral Research Centre "Advanced Blasting Technology" JKMRC, University of Queensland, Brisbane, Australia, AMIRA P93D (1987-1990), Final Report, 1991.

[14] Kahriman, A., Özkan, Ş. G., Sül, Ö. L., Demirci, A. "Estimation of the powder factor in bench blasting from the Bond work index", Mining Technology, 110(2), pp. 114-118, 2001. https://doi.org/10.1179/mnt.2001.110.2.114

[15] Langefors, U. Kihlström, B. "The modern technique of rock blasting", Wiley, New York, NY, USA, 1978.

[16] Lilly, P. A. "An empirical method of assessing rock mass blastability", In: Large Open Pit Mining Conference, Newman, Australia, 1986, pp. 89-92.

[17] Olofsson, S. O. "Applied explosives technology for construction and mining", Applex, Ärla, Sweden, 1990.

[18] Pokrovsky, N. M. "Driving Horizontal Workings and Tunnels: Underground Structures and Mines Construction Practices", Mir Publishers, Moscow, Russia, 1980.

[19] Raina, A. K., Haldar, A., Chakraborty, A. K., Choudhury, P. B., Ramulu, M., Bandyopadhyay, C. "Human response to blast-induced vibration and air-overpressure: an Indian scenario", Bulletin of Engineering Geology and the Environment, 63(3), pp. 209-214, 2004. https://doi.org/10.1007/s10064-004-0228-7

[20] Ryu, C.-H., Sunwoo, C., Lee, S.-D., Choi, H.-M. "Suggestions of rock classification methods for blast design and application to tunnel blasting", Tunnelling and Underground Space Technology, 21(3-4), pp. 401-402, 2006. https://doi.org/10.1016/j.tust.2005.12.211

[21] Zare, S. Bruland, A. "Comparison of tunnel blast design models", Tunnelling and Underground Space Technology, 21(5), pp. 533541, 2006.

https://doi.org/10.1016/j.tust.2005.09.001 
[22] Han, J., Weiya, X., Shouyi, X. "Artificial Neural Network Method of Rock Mass Blastability Classification", In: Proceedings of the Fifth International Conference on GeoComputation, London, UK, 2000, pp. 23-28,

[23] Cardu, M., Seccatore, J. "Quantifying the difficulty of tunnelling by drilling and blasting", Tunnelling and Underground Space Technology, 60, pp. 178-182, 2016. https://doi.org/10.1016/j.tust.2016.08.010

[24] Soroush, K., Mehdi, Y., Arash, E. "Trend analysis and comparison of basic parameters for tunnel blast design models", International Journal of Mining Science and Technology, 25(4), pp. 595-599, 2015.

https://doi.org/10.1016/j.ijmst.2015.05.012

[25] Zare, S., Bruland, A. "Estimation model for advance rate in drill and blast tunnelling", presented at International Symposium on Utilization of Underground Space in Urban Areas, Sharm El-Sheikh, Egypt, Nov. 6-7, 2006.

[26] Zare, S., Bruland, A., Rostami, J. "Evaluating D\&B and TBM tunnelling using NTNU prediction models", Tunnelling and Underground Space Technology, 59, pp. 55-64, 2016. https://doi.org/10.1016/j.tust.2016.06.012

[27] Vapnik, V. "The Nature of Statistical Learning Theory", Springer, New York, NY, USA, 2013.

https://doi.org/10.1007/978-1-4757-3264-1

[28] Sain, S. R. "The nature of statistical learning theory", Technometrics, 38(4), p. 409, 1996. https://doi.org/10.1080/00401706.1996.10484565

[29] Guo, H., Nguyen, H., Bui, X.-N., Armaghani, D. J. "A new technique to predict fly-rock in bench blasting based on an ensemble of support vector regression and GLMNET", Engineering with Computers, 37, pp. 421-435, 2021. https://doi.org/10.1007/s00366-019-00833-x

[30] Smola, A. J., Schölkopf, B. "A tutorial on support vector regression", Statistics and Computing, 14(3), pp. 199-222, 2004. https://doi.org/10.1023/B:STCO.0000035301.49549.88
[31] Chang, C.-C., Lin, H.-J. "LIBSVM - A Library for Support Vector Machines", ACM Transactions on Intelligent Systems and Technology, 2(3), Article No. 27, 2007. https://doi.org/10.1145/1961189.1961199

[32] Schölkopf, B., Smola, A. J. "Learning with Kernels: Support Vector Machines, Regularization, Optimization, and Beyond", MIT Press, Cambridge, MA, USA, 2001.

[33] Dibike, Y. B., Velickov, S., Solomatine, D., Abbott, M. B. "Model Induction with Support Vector Machines: Introduction and Applications", Journal of Computing in Civil Engineering, 15(3), pp. 208-216, 2001. https://doi.org/10.1061/(ASCE)0887-3801(2001)15:3(208)

[34] Li, D. T., Yan, J. L., Zhang, L. "Prediction of Blast-Induced Ground Vibration Using Support Vector Machine by Tunnel Excavation", Applied Mechanics and Materials, 170-173, pp. 1414-1418, 2012. https://doi.org/10.4028/www.scientific.net/AMM.170-173.1414

[35] Mahdevari, S., Shirzad Haghighat, H. S., Torabi, S. R. "A dynamically approach based on SVM algorithm for prediction of tunnel convergence during excavation", Tunnelling and Underground Space Technology, 38, pp. 59-68, 2013. https://doi.org/10.1016/j.tust.2013.05.002

[36] Samui, P. "Support vector machine applied to settlement of shallow foundations on cohesionless soils", Computers and Geotechnics, 35(3), pp. 419-427, 2008. https://doi.org/10.1016/j.compgeo.2007.06.014

[37] Shafiei, A., Parsaei, H., Dusseault, M. B. "Rock Squeezing Prediction by a Support Vector Machine Classifier", presented at 46th US Rock Mechanics/GeoMechanics Symposium, Chicago, IL, USA, June, 24-27, 2012.

[38] Shi, X., Zhou, J., Wu, B., Huang, D., Wei, W. "Support vector machines approach to mean particle size of rock fragmentation due to bench blasting prediction", Transactions of Nonferrous Metals Society of China, 22(2), pp. 432-441, 2012. https://doi.org/10.1016/S1003-6326(11)61195-3 